\title{
Incidência de mutação no códon 12 do protoncogene K-ras em carcinoma de próstata humana em uma amostra da população brasileira
}

\author{
The incidence of mutation in codon 12 of the K-ras proto-oncogene in human prostate carcinoma with a \\ Brazilian population sample
}

José Raul Cisternas Gajardo'; Marcos Tobias-Machado²; Lucila Heloisa Simardi; Thiago Domingos Corrêa ${ }^{4}$; Eric Roger Wroclawski ${ }^{5}$

\begin{tabular}{l|l}
\multicolumn{1}{c|}{ Unitermos } & resumo \\
Próstata & $\begin{array}{l}\text { Com o intuito de estudar a participação do gene ras ativado na tumorigênese humana, pesquisamos a } \\
\text { freqüência de mutação pontual no códon } 12 \text { do gene K-ras em espécimes cirúrgicos de pacientes por- } \\
\text { tadores de câncer de próstata. Foi utilizado um grupo controle de pacientes com hiperplasia prostática } \\
\text { benigna (HPB). Os cortes destinados ao estudo foram submetidos a extração do DNA pelo método da } \\
\text { Câncer }\end{array}$ \\
$\begin{array}{l}\text { Reação da polimerase } \\
\text { em cadeia }\end{array}$ & $\begin{array}{l}\text { por clivagem, utilizando-se a enzima de restrição Mval. A eletroforese em gel de agarose permitiu a } \\
\text { verificação da presença de mutações. Constatamos a presença de mutação no códon 12 do gene K-ras } \\
\text { em dois dos } 15 \text { carcinomas de próstata estudados (13,3\%), sendo que nenhuma em pacientes com } \\
\text { KPB. A ocorrência de mutação de 13,3\% na amostra da população brasileira analisada caracteriza uma } \\
\text { incidência intermediária entre as populações japonesa e americana. É pouco provável que a mutação } \\
\text { isolada do K-ras seja um evento significativo na carcinogênese prostática nesta população. }\end{array}$
\end{tabular}

abstract

Aiming to study the participation of activated ras gene on the human tumorogenesis, we have researched the frequency of a punctual mutation in codon 12 of the K-Ras oncogene in surgical specimens of patients with prostate cancer. We used control group of patients with benign prostatic hyperplasia. The pieces addressed to the study was submitted to the extraction of DNA by the proteina kinase method. The isolated fragment amplification was obtained using a polymerase chain reaction followed by clevage with Mval restriction enzime. The electrophoresis process allowed the verification of the mutation presence. We noticed the presence of mutation in codon 12 of the K-ras oncogene in two of 15 prostate carcinomas studied (13.3\%). None of the patients with prostatic benign prostatic hyperplasia presented any mutation. The mutation incidence of $13.3 \%$ on brazilian population sample analysed demonstrated an intermediary incidence between American and Japanese population. It is unlikely that K-ras mutation isolated has a significant role on the prostatic carcinogenesis in this population. 


\section{Introdução}

Estudos experimentais e epidemiológicos têm demonstrado que o câncer é uma doença genética caracterizada por uma série acumulativa de alterações dos genes que modulam diversos mecanismos relacionados a proliferação celular, morte celular programada, angiogênese e expressão de moléculas de adesão( ${ }^{(8,11)}$.

Entre os genes que controlam o crescimento celular encontra-se a família do gene ras, composta por três genes: $\mathrm{K}$-ras, N-ras, e H-ras ${ }^{(28,22)}$.

Mutações pontuais, principalmente nos códons 12, 13 e 61 dos protoncogenes da família ras, ocorrem em aproximadamente $20 \%$ dos tumores humanos. São mais freqüentemente observadas no K-ras (aproximadamente $85 \%$ do total), seguido pelo $\mathrm{N}$-ras (cerca de $15 \%$ ) e pelo $\mathrm{H}$-ras (menos de 1\%). Isto permite a conversão destes protoncogenes em oncogenes ras ativados ${ }^{(8)}$.

O códon 12 protoncogene K-ras, altamente suscetível a mutações (hot spot), é constituído pela seqüência de bases GGT que codifica o aminoácido glicina. As possíveis mutações pontuais que podem ocorrer neste códon são: GGT para CGT (codifica a arginina); GGT para AGT (codifica a serina); GGT para TGT (codifica a cisteína); GGT para GTT (codifica a valina); GGT para GAT (codifica o aspartato); e, finalmente, GGT para GAC (que também codifica o aspartato) $)^{(3)}$.

O protoncogene K-ras codifica uma proteína de 21 $\mathrm{kDa}(\mathrm{p} 21)$, a qual se localiza na membrana plasmática de todas as células humanas. A função fisiológica da p21 é receber um sinal de um receptor de tirosina-quinase. Este permite a ligação de fatores de crescimento na face externa da membrana plasmática, levando, em última instância, a eventos que promovem a proliferação celular. A mutação deste gene, tornando-o um oncogene ativo, desencadeia a proliferação celular descontrolada ${ }^{(3,19)}$.

A atividade mitótica, mediada através da proteína quinase fosfatase-1 (MKP1), pode ser induzida por vários oncogenes através da via ras dependente. Além disso, pode haver inativação da sinalização para a apoptose ${ }^{(13,23)}$.

A importância da mutação dos oncogenes da família ras na carcinogênese do câncer de próstata tem sido controversa ${ }^{(6,16,25)}$. Konishi et al. estudaram a presença de alterações nos genes da família ras em 70 pacientes japoneses e em 31 pacientes americanos, constatando, respectivamente, uma incidência de $12,8 \%$ e $3,2 \%$ de mutações pontuais ${ }^{(18)}$. Estes dados sugerem a existência de um componente genético e/ou ambiental, diferente entre distintas populações e associado à modificação dos oncogenes ras.

Segundo dados do Instituto Nacional do Câncer (Inca), o câncer de próstata é o segundo tipo mais comum no sexo masculino, superado apenas pelo câncer de pele não-melanoma, sendo a quarta causa de óbito por câncer no Brasil(24).

Desta forma, consideramos de interesse verificar a freqüência de mutação do oncogene K-ras em uma amostra da população da cidade de São Paulo (SP) portadora de carcinoma de próstata. Esta apresenta grande diversidade genética, uma vez que se desconhece a freqüência de mutação deste gene em nosso meio. Assim, contribui-se para uma maior compreensão da participação do gene ras ativado na tumorigênese humana, mais especificamente na população brasileira.

\section{Material e método}

Blocos de parafina provenientes de 15 espécimes cirúrgicos de carcinoma de próstata (CaP) e 15 procedentes de biópsias de pacientes portadores de HPB foram coletados dos arquivos do Departamento de Patologia da Faculdade de Medicina do $A B C$ (FMABC).

Lâminas obtidas deste material foram fixadas em hematoxilina e eosina para confirmação diagnóstica e seleção das áreas mais representativas. $\mathrm{O}$ diagnóstico histopatológico seguiu a classificação da Organização Mundial da Saúde (OMS). A contaminação foi evitada com troca de lâminas entre cada amostra.

Dois cortes de cada espécime, com 8 micrômetros $(\mu \mathrm{m})$ de espessura, foram desparafinizados com $1 \mathrm{ml}$ de xileno, homogeneizados à temperatura ambiente, por 15 minutos, e centrifugados a $12.000 \mathrm{~g}$ durante 3 minutos. Seguiu-se de lavagem com etanol absoluto por duas vezes, sendo as amostras centrifugadas e evaporadas à temperatura ambiente, de acordo com a técnica descrita por Hruban et al. ${ }^{(12)}$.

\section{Extração do DNA das amostras de tecido}

O DNA genômico dos tecidos foi obtido através da utilização do kit de extração (DNeasy, Tissue Kit, Quiagen, Valencia, CA, USA), de acordo com as recomendações do fabricante.

Em resumo, o tecido foi digerido com 100 microlitros $(\mu \mathrm{l})$ de tampão ATL (Lysis Buffer), contendo 200ug/ml de proteinase K (Quiagen, Valencia, CA, USA), e incubado a 
$37^{\circ} \mathrm{C}$ durante 16 horas. A posterior inibição desta enzima foi realizada a $90^{\circ} \mathrm{C}$ por 10 minutos. A alíquota de $10 \mu \mathrm{l}$ de solução precipitante de proteína ( $\mathrm{LiCl} 3 \mathrm{M}$ ) foi acrescenta$\mathrm{da}$, seguida por curta centrifugação. $O$ sobrenadante foi removido e o DNA, precipitado, utilizando-se isopropanol seguido de centrifugação, durante 10 minutos, a $12.000 \mathrm{~g}$. Quando o precipitado de DNA ficou seco, o mesmo foi dissolvido em 50 $\mu$ l de TE [10 mM Tris-HCl, 1 mM EDTA $\left(\mathrm{pH}\right.$ 8)] e mantido à temperatura de $-20^{\circ} \mathrm{C}$ até a realização da amplificação.

\section{Reação de polimerização em cadeia}

A reação em cadeia de polimerase (PCR) teve como finalidade a amplificação específica da região de 157 pares de bases contendo o códon 12 do gene K-ras. Para tal foram utilizados os oligonucleotídeos A e B, com suas respectivas bases com erro de pareamento [primers mismatches (GIBCO BRL)] sublinhadas na seqüência abaixo, idealizada por Jiang et. al.(15):

\section{A - 5' ACT GAA TAT AAA CTT GTG GTA GTT GGA CCCT 3' B - 5' TCA AAG AAT GGT CCT GEA CC 3'}

A técnica da PCR foi realizada seguindo as instruções indicadas pelo fabricante (Promega). Em resumo, numa amostra contendo $25 \mathrm{ng}$ de DNA (1 a 10ul), foram adicionados 25 ul da solução-mãe de PCR, que consistia em: tampão Tris-HCl $10 \mathrm{mM}(\mathrm{pH} 8,8), \mathrm{MgCl}_{2} 2 \mathrm{mM}, \mathrm{KCl} 60 \mathrm{mM}$, $125 \mathrm{uM}$ de cada dNTP, 50 pMoles de cada primer e $4 \mathrm{UI}$ de Taq DNA-polimerase.

As condições de amplificação da PCR foram de $94^{\circ} \mathrm{C}$ por 2 minutos, seguida de 12 ciclos, sendo que cada um destes utilizou temperaturas de $96^{\circ} \mathrm{C}$ por um minuto, $55^{\circ} \mathrm{C}$, durante este mesmo tempo e $72^{\circ} \mathrm{C}$ por 30 segundos. Um controle negativo (sem DNA) foi empregado em cada ensaio.

Após a PCR, os produtos obtidos foram submetidos à digestão com $10 \mathrm{U}$ de endonuclease $\mathrm{Mval}$, em tampão Tris$\mathrm{HCl}, \mathrm{pH} 8,5$, em um volume total de $25 \mu \mathrm{l}$, de acordo as especificações do fabricante (Amersham-Biosciences).

Com o intuito de aumentar a sensibilidade para detecção de mutações puntuais do gene K-ras, utilizamos o aprimoramento da técnica de PCR proposto por Levi et al.(21). Esta consiste na amplificação do produto da primeira PCR já digerido, com Mval, empregando-se agora os primers mismatches A e C (GIBCO BRL) contendo a seguinte seqüência de bases com erro de pareamento:

\section{A - 5' ACT GAA TAT AAA CTT GTA GTT GGA CCCT 3' C - 5' TAA TAT GTC GAC TAA AAC TTT ACC TC $3^{\prime}$}

Um volume alíquota de $1 \mu \mathrm{l}$ do produto de digestão da primeira PCR foi utilizado para a prática da segunda amplificação, cujas condições foram de 35 ciclos de $96^{\circ} \mathrm{C}$ por um minuto, $55^{\circ} \mathrm{C}$ por este mesmo tempo e $72^{\circ} \mathrm{C}$ por 30 segundos, seguida de nova digestão com $\mathrm{Mval}$, de acordo com a técnica descrita pelo fabricante (Amercham-Biosciences). Assim, aumentou-se a sensibilidade do método de 1:10 para 1:512 (alelos mutantes:alelos normais).

\section{Análise da PCR}

O produto da reação da PCR $(5 \mu \mathrm{l})$ foi submetido a eletroforese em gel de agarose a $1 \%$, a 80 volts, durante 30 minutos, corado com brometo de etídio. A presença ou ausência de mutação em cada amostra foi verificada através da comparação com um marcador de peso molecular (Ladder123 - Amersham-Biosciences).

A documentação dos resultados foi feita através da utilização de luz ultravioleta transmitida e da fotografia do gel de agarose, tendo sido usado o filme Polaroid do tipo 667 (ASA 3000).

Os dados clínicos e demográficos dos pacientes foram avaliados retrospectivamente através de questionário. Nos casos de câncer, o estadiamento utilizado foi o sistema TMN (1997), e a graduação histológica foi obtida através do escore de Gleason ${ }^{(9)}$.

\section{Resultados}

Foram obtidas 15 amostras anatomopatológicas de pacientes com câncer de próstata e 15 de pessoas com HPB.

A idade média dos indivíduos incluídos neste estudo foi de 68,7 anos. Dos 15 pacientes estudados, $46,7 \%$ eram de etnia branca e $53,3 \%$, negra e parda.

Em relação ao estadiamento patológico das amostras de tecido prostático, provenientes dos pacientes com CaP, $40 \%$ dos tumores eram localizados (estágios 1 e 2); $40 \%$, localmente avançados (estágio 3); e 20\%, metastáticos (estágio 4). No que se refere à graduação histológica desses pacientes, segundo o escore de Gleason, $60 \%$ dos tumores foram classificados como bem diferenciados (escore entre 2 e 6); $26,7 \%$, como moderadamente diferenciados (escore 7); e 13,3\%, como indiferenciados (escore entre 8 e 10). 
A correlação da mutação do códon 12 do K-ras com idade, raça, estadiamento patológico e escore de Gleason dos pacientes pode ser observada na Tabela 1 .

A PCR e a análise do polimorfismo do fragmento de comprimento variável, obtido por clivagem, com enzima de restrição, permitiram a amplificação da região específica de 157 pares de base $(\mathrm{pb})$ que continham o códon 12 do gene K-ras. Em todas as amostras do DNA genômico do tecido prostático houve clivagem total.

Observamos mutação do códon 12 do K-ras em duas amostras de CaP (13,3\%). Não verificamos tal alteração em nenhuma amostra de pacientes com HPB.

Os dois pacientes que apresentaram modificação do K-ras possuíam idade superior a 60 anos.

Em relação ao estadiamento patológico dos tumores, nestes dois indivíduos observamos que um apresentava tumor localizado e o outro, metastático. No que se refere à graduação histológica, segundo o escore de Gleason, um paciente apresentou tumor bem diferenciado (escore entre 2 e 6) e o outro, indiferenciado (escore entre 8 e 10).

\section{Estratificação através de idade, grupo étnico, estágio tumoral e graduação histológica dos 15 pacientes com CaP, segundo a}

presença ou náo de mutação no

\begin{tabular}{llc}
\hline Critérios avaliados & \multicolumn{2}{c}{ Número de casos } \\
& $\begin{array}{c}\text { Com mutação } \\
\text { K-ras }\end{array}$ & $\begin{array}{c}\text { Sem mutação } \\
\text { K-ras }\end{array}$ \\
Idade (anos) & & \\
$50-60$ & 0 & 4 \\
$60-70$ & 1 & 7 \\
> 70 & 1 & 2 \\
Etnia & & \\
Branca & 1 & 6 \\
$\quad$ Parda/negra & 1 & 7 \\
Estadiamento & & \\
I, II (localizado) & 1 & 5 \\
III (localmente avançado) & 0 & 6 \\
IV (metastático) & 1 & 2 \\
Escore de Gleason & & \\
2-6 (bem diferenciado) & 1 & 8 \\
7 (moderadamente & 0 & 4 \\
$\quad$ diferenciado) & & \\
8-10 (indiferenciado) & 1 & \\
\hline
\end{tabular}

\section{Discussão}

Os genes da família ras possuem importante papel no controle de diversas vias de sinalização celular que estão intimamente relacionadas à regulação da proliferação das células e a sua transformação maligna (3,8, 22).

A presença de mutações pontuais nos protoncogenes da família ras (K-ras, N-ras e H-ras), principalmente a mutação no códon 12 do K-ras, é uma das alterações genéticas mais freqüentes, estando presente em até $20 \%$ dos diversos tumores do ser humano, incluindo, entre outros, os de próstata, pâncreas, pulmão, tireóide, bexiga, rim e os colorretais ${ }^{(8,20)}$.

Nestes casos, a ativação do protoncogene K-ras contribui de maneira significativa em muitos dos aspectos característicos de tumores malignos, como crescimento celular desordenado, alterações no mecanismo de morte celular programada (apoptose) e capacidade de invasão celular e de indução da angiogênese $e^{(3,8,22)}$.

Estes dados apontam para a importância da via ras dependente, tanto em condições fisiológicas como na presença da mutação dos oncogenes desta família. Desta forma, processos proliferativos como a HPB e o câncer de próstata podem ser influenciados por tais alterações ${ }^{(4)}$.

Apesar da fraca expressão da proteína p21, produto final de tradução da via ras dependente, ter sido detectada em pacientes com HPB, existem evidências da ausência de mutação dos genes da família ras em indivíduos com esta doença ${ }^{(1,5,26)}$.

Nossos resultados são compatíveis com esta última observação, reforçando não existir relação entre a alteração do ras e a patogênese da HPB.

Em relação ao câncer de próstata, algumas evidências levaram a crer que a ativação dos oncogenes ras tivesse participação na gênese deste tumor ${ }^{(1,5,26)}$.

Foram então realizados trabalhos em linhagens celulares de humanos, mostrando que a presença de mutação gênica em populações ocidentais tem sido menor que 5\%, enquanto que as estatísticas japonesas revelaram incidências mais significativas, atingindo até $25 \%$. Tais estudos indicam que o oncogene ras está mais relacionado ao câncer de próstata no Japão do que nos países americanos ${ }^{(17,18,29-31)}$ (Tabela 2).

Esta discrepância de resultados poderia ser explicada por diversos fatores técnicos, tais como a amostra tumoral, os métodos analíticos e a qualidade do DNA extraído das amostras teciduais. 
Apesar destes fatos, existe a real possibilidade de que os fatores étnico e geográfico sejam significativamente importantes na alteração dos genes da família ras, uma vez que os resultados de diferentes autores tenderam a manter a taxa de mutação em cada grupo étnico ${ }^{(7,29)}$.

Dados de necropsia indicam que a incidência de carcinoma de próstata latente entre diferentes populações é bastante semelhante. Já o clinicamente manifestado é muito mais comum nas populações americanas do que nas asiáticas ${ }^{(7)}$.

Shiraishi et al. observaram mutação dos oncogenes ras em 20 de 81 amostras (24\%) de CaP em japoneses. A alteração ocorreu em três de 22 carcinomas latentes e em 17 de 59 tumores malignos nos mais variados estádios clínicos, inclusive em metástase. Das 20 mutações, 13 ocorreram no códon 12 do K-ras; cinco, no códon 61 do H-ras; e duas, no códon 13 do H-ras ${ }^{(30)}$.

Estes acontecimentos levam a crer que os eventos iniciais da carcinogênese do câncer de próstata são comuns, enquanto que sua capacidade de manifestação clínica, caracterizada pelo estadiamento e pela graduação histológica, é mediada por diferentes eventos genéticos, incluindo a ativação dos protoncogenes da família K-ras.

Watanabe et al. demonstraram claramente o significado das diferentes freqüências de ativação dos oncogenes ras em amostras de carcinoma latente de grupos étnicos diversos, obtendo índice de mutação de 30\% em colombianos, $24 \%$ em japoneses e $5 \%$ em havaianos e americanos continentais ${ }^{(32)}$. Além disso, as alterações predominantes nos carcinomas latentes foram as do K-ras, enquanto que as do H-ras predominaram nos cânceres clinicamente manifestos.

Os dados deste estudo, ressaltado o pequeno número amostral, sugerem que as mutações do K-ras não estão associadas à progressão do estado latente para a doença clínica. Alguns autores acreditam que, possivelmente, estas alterações representem exatamente o contrário, ou seja, a ausência de progressão para um estágio mais agressivo. Há, no entanto, alguma controvérsia quanto a

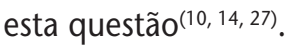

A população brasileira apresenta características genéticas diversas, uma vez que existe grande miscigenação de populações oriundas dos continentes americano, europeu e africano, além de uma pequena influência asiática.

O presente trabalho possui limitações por ter estudado um pequeno número de pacientes, o que poderia contribuir para a não-quantificação exata da freqüência de mutação do gene K-ras na população brasileira.

Além disso, a metodologia empregada neste estudo nos possibilitou apenas a detecção da presença ou da ausência de alteração no códon 12 do protoncogene K-ras, não nos permitindo descrever com exatidão qual a mutação pontual específica ocorrida em cada uma das duas amostras de tecido que apresentaram essa alteração.

Constatamos que a mutação do códon 12 do K-ras ocorreu em duas das 15 amostras estudadas, totalizando $13,3 \%$, o que caracteriza uma incidência intermediária entre as populações americana e japonesa (Tabela 2). Talvez a pesquisa de outros genes da família ras, neste trabalho, resultasse em uma maior freqüência de alterações.

Incidência de mutação dos oncogenes da familia ras em câncer de próstata, de acordo com Tabela 2 pais de origem e estadiamento dos tumores estudados

\begin{tabular}{cccccc}
\hline Referência & Ano & Incidência (\%) & Mutação & País & Estadiamento \\
$(25)$ & 1992 & 0 & Nenhuma & EUA & II, III \\
$(6)$ & 1990 & 4 & Códons 12 e 61 H-ras & EUA & II, III, IV \\
$(18)$ & 1997 & 13 & Códons 12 K-ras e 12 N-ras & Japão & I, II, III, IV \\
$(18)$ & 1997 & 3 & Códons 12 K-ras & EUA & II \\
$(26)$ & 1995 & 0 & Nenhuma & França & I, II, III, IV \\
$(17)$ & 1992 & 26 & Códons 12 K-ras & Japão & Latente \\
$(31)$ & 1994 & 22 & Códons 12 e 61 K-ras, 13 e 61 H-ras & Japão & II, III, IV \\
$(30)$ & 1998 & 25 & Códons 12 K-ras, 13 e 61 H-ras & Japão & I, II, III, IV \\
$(32)$ & 1994 & 24 & Códons 12 K-ras, 12 N-ras e 61 H-ras & Japão & Latente \\
$(10)$ & 1991 & 5 & Códon 61 H-ras & EUA & II, III, IV \\
$(2)$ & 1992 & 24 & Códons 61 K-ras, 12 N-ras e 61 H-ras & Japão & I, II, III, IV \\
\hline
\end{tabular}


Foram considerados, no presente estudo, apenas pacientes com câncer clinicamente manifesto, impossibilitando-nos qualquer comparação com carcinomas latentes. Obtivemos a mutação em um paciente com doença extensamente localizada e em um com doença metastática.

Concluímos que, apesar do pequeno número de pacientes estudados em cada um dos grupos, a mutação isolada do oncogene ras provavelmente não seja um evento significativo na gênese universal do câncer de próstata. Consideramos que sejam necessários estudos com maior tamanho amostral para que se possa correlacionar o grau histológico dos tumores prostáticos com a freqüência de alteração do gene K-ras.

A baixa positividade da mutação do gene K-ras $(13,3 \%)$ em uma pequena amostra de pacientes não admite conclusões a respeito do valor prognóstico desta mutação, embora existam evidências de que a via de expressão do ras possa ter importante função na gênese do câncer de

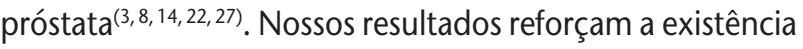
de uma variabilidade genética nos eventos carcinogênicos entre as diversas populações.

\section{Referências}

I. AGNATNTIS, N. J. et al. Comparative immunohistochemical study of ras p2I oncoprotein in adenomatous hyperplasia and adenocarcinoma of tue prostate gland. Anticancer Res, V. I4, n. 5B, p. $2135-40,1994$.

2. ANWAR, $K$. et al. Presence of ras oncogene mutations and human papillomavirus DNA in human prostate carcinomas. Cancer Res, v. 52, n. 21 , p. 5991-6, 1992.

3. BOS, J. L. Ras oncogene in human cancer: a review. Cancer, v. 49, p. $4682-9,1989$.

4. BROTHMAN, A. et al. Frequency and pattern of karyotypic abnormalities in human prostate cancer. Cancer Res, v. 50, p. 3795-803, 1990.

5. BUSHMAN, E. C. et al. Immunohistochemical staining of ras $p 21$ : staining in benign and malignant prostate tissue.J Urol, v. 153 , n. I, p. 233-7, 1995.

6. CARTER, B. S. et al. Ras gene mutations in human prostate cancer. Cancer Res, v. 50, n. 21, p. 6830-2, 1990.

7. DAMBER, J. E. et al. Epidemiology of prostate cancer. In: MURPHHY, G. et al. L. $2^{\text {nd }}$ International consultation on prostate cancer. United Kingdom: Plymbridge Distribution Ltd, 1999.

8. DOWNWARD, J. Targeting Ras signalling pathways in cancer therapy. Nat Rev Cancer, v. 3, n. I, p. I I-22, 2003.

9. GITTES, R.F. Carcinoma of the prostate. N Engl J Med, v. 324, n. 4, p. 236-45, 1991.

10. GUMERLOCK, P. H. et al. Activated ras alleles in human carcinoma of the prostate are rare. Cancer Res, v. 5I, n. 6, p. |632-7, 199|.

I।. HALL, E. J. Etiology of cancer: phisical factors. In: DE VITA JUNIOR,V.T.; HELLMAN, S.; ROSENBERG, S. A. Principles \& Practice of Oncology. 5. ed. Philadelphia: Lippincortt- Raven, 1997, p. 203-18.

12. HRUBAN, R. H. et al. K-ras oncogene activation in adenocarcinoma of the human pancreas. A study of 82 carcinomas using a combination of mutant-enriched polymerase chain reaction analysis and allele-specific oligonucleotide hybridization. Am J Pathol, v. I43, p. I4554, 1993.
13. HRZENJAK, M. et al. Fibroblast growth factor-2 andTPA enhance prostate cancer cell proliferation and active members of ras and PKC signal tranduction pathways. Recept SignlaTransduct, v. 7, n. 4, p. 207-19, 1997.

14. ISAACS, W. B. et al. Molecular biology of prostate cancer progression. Cancer Surv, v. 23, p. 19-32, 1995.

15. JIANG, W. et al. Rapid detection of ras oncogenes in human tumors: applications to colon esophageal and gastric cancer. Oncogene, v. 4, p. 923-8, 1989.

16. KONISHI, N. et al. Genetic changes in prostate cancer. Pathol Int, v. 47, n. II, p. 735-47, 1997.

17. KONISHI, N. et al. K-Ras activation and ras p2I expression in latent prostatic carcinoma in Japanese men. Cancer, v. 69, n. 9, p. 2293-9, 1992.

18. KONISHI, N. et al. Comparison of Ras activation in prostate carcinoma in Japanese and American men. Prostate, v. 30, n. I, p. 53-7, 1997.

19. KONISHI, N. et al. Intratumor cellular heterogeneity and alterations in ras oncogene and p53 tumor suppressor gene in human prostate carcinoma. Am J Pathol, v. I 47, n. 4 , p. II I2-22, 1995.

20. KUBRUSLY, M. S. et al. Detection of K-Ras point mutation at codon 12 in pancreatic diseases: a study in a brazilian casuistic. JOP, v. 3, n. 5, p. I 44-5I, 2002.

21. LEVI, S. et al. Multiple K-ras codon 12 mutations in cholangiocarcinomas demostraded with a sensitive polymerase technique. Cancer Res, v. 5 I, p. 3097-502, |991.

22. LOWRY, D. R. et al. Function and regulation of ras. Annu Rev Biochem, v. 63, p. 85I-91, 1993.

23. MAGI-GALUZZI, C. et al. Mitogen activity protein kinase phosphatase $I$ is overexpressed in prostate cancers and inversely related apoptosis. Lab Invest, v. 76, n. I, p. 37-51, 1997.

24. MINISTÉRIO DA SAUUDE DO BRASIL. Instituto Nacional do Câncer. Coordenação de programas de controle de câncer - Pró-onco. O problema do câncer no Brasil. 4. ed. Rio de Janeiro, 1997. 
25. MOUL, J.W. et al. Infrequent ras oncogene mutations in human prostate cancer. Prostate, v. 20, n. 4, p. 327-38, 1992.

26. MOYRET-LALLE, C. et al. Ras, p53 and HPV status in benign and malignant prostate tumors. Integral J Cancer, v. 64, n. 2, p. 124-9, 1995.

27. PEEHL, D. M. Oncogenes in prostate cancer. an update. Cancer, v. 7I, suppl. 3, p. I I59-64, 1993.

28. REDDY, E. P. et al. A point mutation is responsible for the acquisition of transforming properties by the T24 human bladder carcinoma oncogene. Nature, v. 300, n. 5.888, p. $149-52,1982$
29. SHIMIZU, H. et al. Cancers of the prostate and breast among Japanese and white immigrants in Los Angeles County. Br J Cancer, v. 63, n. 6, p. 963-6, 1991.

30. SHIRAISHI, T. et al. Mutations of Ras genes are relatively frequent in Japanese prostate cancers: pointing to genetic differences between populations. Anticancer Res, v. I8, n. 4B, p. 2789-92, 1998.

3I. SUZUKI, H. et al. State of adenomatous polyposis coli gene and Ras oncogenes in japanese prostate cancer. Jpn J Cancer Res, v. 85, n. 8, p. 847-52, 1994.

32. WATANABE, $M$. et al. International comparison on ras gene mutations in latent prostate carcinoma. Int J Cancer, v. 58, n. 2, p. 174-8, 1994. 